\title{
Meta-analysis of vitamin D and lung function in patients with asthma
}

Jian Liu', Yong-Quan Dong ${ }^{2}$, Jie Yinn ${ }^{4}$, Jian Yao ${ }^{3}$, Jie Shen ${ }^{4}$, Guo-Jie Sheng ${ }^{1}$, Kun Li ${ }^{1}$, Hai-Feng Lv', Xing Fang ${ }^{1}$ and Wei-Fang $\mathrm{Wu}^{1 *}$ (iD

\begin{abstract}
Background: There is growing literature suggesting a link between vitamin D and asthma lung function, but the results from systematic reviews are conflicting. We conducted this meta-analysis to investigate the relation between serum vitamin $\mathrm{D}$ and lung function in asthma patients.

Methods: Major databases, including OVID, MEDLINE, Web of Science and PUBMED, were searched until 10th October 2018. All published observational studies related to vitamin D and asthma were extracted. All meta-analyses were performed using Review Manager 5.3.5.

Results: This quantitative synthesis found that asthma patients with low vitamin $D$ levels had lower forced expiratory volume In $1 \mathrm{~s}$ (FEV1) (mean difference $(\mathrm{MD})=-0.1,95 \% \mathrm{Cl}=-0.11$ to $-0.08, p<0.01 ; 12=49 \%, p=0.12$ ) and FEV1\% $(\mathrm{MD}=-10.02,95 \% \mathrm{Cl}=-11$ to $-9.04, \mathrm{p}<0.01 ; 12=0 \%, p=0.82)$ than those with sufficient vitamin $\mathrm{D}$ levels. A positive relation was found between vitamin $D$ and FEV1 $(r=0.12,95 \% \mathrm{Cl}=0.04$ to $0.2, p=0.003 ; 12=59 \%, p=0.01)$, FEV1\% $(r=0.19,95 \% \mathrm{Cl}=0.13$ to $0.26, p<0.001 ; 12=42 \%, p=0.11)$, forced vital capacity (FVC) $(r=0.17,95 \%$ $\mathrm{Cl}=0.00$ to $0.34, p=0.05 ; 12=60 \%, p=0.04)$, FEV1/FVC ( $r=0.4,95 \% \mathrm{Cl}=0.3$ to $0.51, p<0.001 ; 12=48 \%, p=0.07)$, and the asthma control test (ACT) ( $r=0.33,95 \% \mathrm{Cl}=0.2$ to $0.47, \mathrm{p}<0.001 ; 12=0 \%, p=0.7)$. Subgroup analysis indicated that the positive correlation between vitamin $\mathrm{D}$ and lung function remained significant in both children and adults.

Conclusions: Our meta-analysis suggested that serum vitamin D levels may be positively correlated with lung function in asthma patients. Future comprehensive studies are required to confirm these relations and to elucidate potential mechanisms.
\end{abstract}

Keywords: Vitamin D, Asthma, Lung function

\section{Background}

Asthma is a common inflammatory disorder of the air passages that involves many cellular elements, such as mast cells, eosinophils and $\mathrm{T}$ helper (Th) lymphocytes. Asthma is a major public health concern worldwide because of the increasing prevalence of the condition, along with its negative influence in the community with regard to extensive health care costs and deteriorating quality of life [1]. The occurrence and development of asthma is influenced by various

\footnotetext{
* Correspondence: wwficu@zju.edu.cn

${ }^{1}$ Department of Intensive Care Unit, the First Affiliated Hospital, College of

Medicine, Zhejiang University, Hangzhou, Zhejiang Province, China

Full list of author information is available at the end of the article
}

factors, incorporating genetic, environmental, and ethnic factors, as well as socioeconomic status [2]. A subgroup of asthmatics was shown to manifest a decreased response to standard therapy and experience poorer lung function and more frequent exacerbation. To improve clinical outcomes of patients with asthma and quality of life, methods to slow asthma lung function exacerbations are urgently needed.

The results from studies of vitamin D and the clinical prognosis of asthma patients have led to conflicting messages. A few observational studies suggested that lower $25(\mathrm{OH}) \mathrm{D}$ levels were associated with worse glucocorticoid responsiveness, greater exacerbation frequency,

(c) The Author(s). 2019 Open Access This article is distributed under the terms of the Creative Commons Attribution 4.0 International License (http://creativecommons.org/licenses/by/4.0/), which permits unrestricted use, distribution, and reproduction in any medium, provided you give appropriate credit to the original author(s) and the source, provide a link to the Creative Commons license, and indicate if changes were made. The Creative Commons Public Domain Dedication waiver (http://creativecommons.org/publicdomain/zero/1.0/) applies to the data made available in this article, unless otherwise stated. 
worse lung function and substantially more severe asthma symptoms [3-5]. However, Kang, Q. et al. [6] enrolled 96 children with asthma and found that vitamin D levels were not associated with FEV1 (forced expiratory volume in one second), FVC (forced vital capacity) and FEV1/FVC levels $(p>0.05)$. Reviews and meta-analysis evaluating the current evidence of the association between serum vitamin $\mathrm{D}$ and asthma lung function have also been published; two reported no protective effects of vitamin D supplementation on asthma lung function $[7,8]$, two reported positive effects $[9,10]$, and two did not conduct a meta-analysis of the outcome of pulmonary function $[11,12]$. The conclusions are mixed, and furthermore the study populations included only children. However, more research has been published on this subject in recent years. Hence, we conducted a systematic meta-analysis of observational studies with substantially more evidence to specifically investigate the relation between serum $25(\mathrm{OH}) \mathrm{D}$ and asthma lung function in both adults and children.

\section{Methods}

The Meta-analysis of Observational Studies in Epidemiology (MOOSE) [13] and the Preferred Reporting Items for Systematic Reviews and Meta-Analyses (PRISMA) [14] were applied in this study.

\section{Eligibility criteria}

Eligible clinical studies were defined based on the following criteria: (1) study design was observational; (2) participants were humans of all ages; (3) asthma was diagnosed according to the Global Initiative for Asthma (GINA) or relevant guidelines; (4) content was related to vitamin D and asthma; (5) outcome measures included lung function, such as FEV1, FEV1\%, FVC, and asthma symptom scores such as the Asthma Control Test (ACT); and (6) language was restricted to English only.

\section{Exclusion criteria}

(1) Randomised controlled trials (RCTs) evaluating the relation between vitamin $\mathrm{D}$ supplementation and asthma, as this was not the goal of the review; (2) studies assessing maternal serum levels of vitamin D and the incidence of asthma in children.

\section{Data sources and study selection}

An electronic search was conducted in the following databases: OVID, MEDLINE, Web of Science and PUBMED, for studies published up to 10th October 2018 using the key words asthma, vitamin D, and lung function. The search strategy was developed by two investigators in duplicate and independently according to standardised and pilot-tested selection criteria. Review articles and reference lists of observational publications were manually searched for any possible supplementary references. Any dispute was resolved by mutual consensus with a third investigator.

\section{Data extraction and quality assessment}

Independently, the same reviewers extracted and recorded necessary information from each enrolled study using a standard form recommended by Cochrane [15], which included publication year, study design, authors, country, participants and population, demographic characteristics and measurements. In cases of missing data, we contacted the corresponding authors via email to ask for the full original data. Once extraction was completed, the data were reviewed to identify duplicate studies and duplicate reporting of populations; only the most comprehensive studies were retained.

The Newcastle-Ottawa Scale (NOS) was applied to assess the quality of the observational studies (casecontrol and cohort studies) [16]. Two independent assessors conducted the quality assessment, and any disagreement was settled by reaching a consensus or consulting a third researcher.

\section{Statistical methods}

An estimate of the pooled correlation coefficient ( $r$ ) between vitamin $\mathrm{D}$ and asthma lung function was calculated by combining the standard errors (SEs), and Fisher's $\mathrm{z}$ transformation was calculated by the following formulas. We calculated SEs via formula 1 and formula 2. Each correlation coefficient was transformed by Fisher's z formula (Formula 3). The pooled results were calculated using the generic inverse variance method, after which all the values were converted back to the original correlation coefficient metric (Formula 4). (Formulas 1-4 are shown in Additional file 2: Figure S1) [17, 18]. For studies reporting their outcomes as continuous data, we counted the mean difference when studies used the same measurement and the standardised mean difference when they used different measurements. We tested the results for homogeneity by using the I2 statistics (I $2 \geqq 75 \%$ for evident heterogeneity) and Q ( $p>0.10$ in the Chi-square test for low heterogeneity) [19]. The obtained data were pooled with the DerSimonian \& Laird random-effects models to acclimatise variety [20]. Otherwise, a fixed-effects model was used when there was no obvious heterogeneity [21]. A $P$ value less than 0.05 was considered statistically significant. Funnel plots were applied to explore the possibility of publication bias. For studies providing 
$r 2$ values, the $r$ values were calculated using the $r 2$ values in the paper and by measuring the graphical representation to confirm the sign. For statistical convenience, the quartile was converted to the mean and standard deviation and the unit of measurement for serum vitamin D levels was unified to $\mathrm{ng} / \mathrm{ml}$. Sensitivity analysis was executed by omitting each study in turn to evaluate the reliability and validity of the pooled results. Review Manager (Version 5.3.5, The Nordic Cochrane Centre, The Cochrane Collaboration, Copenhagen, 2014) was applied for data acquisition and analysis.

\section{Results}

\section{Search results}

The flow diagram for study selection is displayed in Fig. 1. The electronic database search identified a total of 2142 citations. After duplicate publications were removed, 942 studies were included. After evaluating the titles and abstracts at level 1 screening, 82 records were included. Assessment of the full text at level 2 screening removed another 24 articles. In total, 27 studies were ultimately included. A majority of the enrolled studies were of moderate to high quality based on the NOS scores.

\section{Study characteristics}

Table 1 and Table 2 describe the characteristics of the included studies. The 27 studies were published in English between 2010 and 2018. There were 19 crosssectional studies, six case-control studies and 2 cohort studies. Eighteen articles evaluated children, and the remaining 9 articles involved adults. Included studies were from both developing and developed countries: six studies were conducted in the USA, four in Turkey, three in China, two in Italy, two in the UK, two in Germany, and two in Thailand, while the other 6 were conducted in Iran, Boston, India, Jordan, Saudi Arabia and Macedonia. The extracted data about outcome measurements were as follows: the correlations between vitamin D and FEV1\% (10 studies), FEV1 (13 studies), FEV1/FVC (12 studies), FVC\% (2 studies), FVC (8 studies), ACT (asthma control test) scores (6 studies). Our analysis also included three groups to compare the mean difference in FEV1\% (4 studies), FEV1 (8 studies), and FEV1/FVC (6 studies) between vitamin D deficiency and insufficiency patients and vitamin D sufficiency patients.

Furthermore, the categorisation thresholds and definitions of 25(OH)D deficiency, insufficiency and sufficiency varied across the studies. The most frequently used categorical levels to describe serum 25(OH)D deficiency, insufficiency and sufficiency were $<20 \mathrm{ng} / \mathrm{ml}$
(50 nmol/l), $20-29.9 \mathrm{ng} / \mathrm{ml}(50-74.9 \mathrm{nmol} / \mathrm{l})$ and $\geq 30$ $\mathrm{ng} / \mathrm{ml}(\geq 75 \mathrm{nmol} / \mathrm{l})$, respectively.

\section{Different lung function in asthma patients with different vitamin D values}

This quantitative synthesis found that asthma patients with low vitamin D levels had lower FEV1 $(\mathrm{MD}=-0.05$, $95 \% \mathrm{CI}=-0.06$ to $-0.05, p<0.01 ; \mathrm{I} 2=87 \%, p<0.01)$, FEV1\% $(\mathrm{MD}=-7.11,95 \% \mathrm{CI}=-13.23$ to $-0.98, p=$ $0.02 ; \mathrm{I} 2=78 \%, p<0.01)$ and FEV1/FVC $(\mathrm{MD}=-5.14$, $95 \% \mathrm{CI}=-5.48$ to $-4.80, p<0.01 ; \mathrm{I} 2=80 \%, p<0.01)$ than those with sufficient vitamin D levels. Sensitivity analysis excluded four outliers [29, 45, 46] from the FEV1 group, one outlier [48] from the FEV1\% group and one outlier [27] from the FEV1/FVC group. The final results were as follows: FEV1 $(\mathrm{MD}=-0.1,95 \% \mathrm{CI}=$ -0.11 to $-0.08, p<0.01 ; \mathrm{I} 2=49 \%, \quad p=0.12), \quad \mathrm{FEV} 1 \%$ $(\mathrm{MD}=-10.02,95 \% \mathrm{CI}=-11$ to $-9.04, p<0.01 ; \mathrm{I} 2=$ $0 \%, p=0.82)$ and FEV1/FVC (MD $=-1.52,95 \% \mathrm{CI}=$ -3.18 to $0.14, p=0.07$; I2 $=35 \%, p=0.19$ ) (Fig. 2a-c).

\section{Relation between vitamin D and lung function in asthma patients}

Thirteen studies described the relationship between vitamin D and FEV1. A total of 290 adults and 545 children were included. The mean vitamin $\mathrm{D}$ concentrations were $21.5 \pm 11.40 \mathrm{ng} / \mathrm{ml}$ in adults and $21.11 \pm$ $14.50 \mathrm{ng} / \mathrm{ml}$ in children. The pooled $\mathrm{r}$ was $0.12(95 \%$ CI $0.05-0.19, p<0.001)$ and was highly heterogeneous $\mathrm{I} 2=91 \%(\mathrm{p}<0.001)$. After sensitivity analysis, removing Alyasin, S. et al., Kang, Q.2018. et al. and Sutherland, E. R et al. [6, 23, 24], (the three outliers), this heterogeneity was significantly reduced with little impact on the outcome $(\mathrm{r}=0.12,95 \% \mathrm{CI}=0.04$ to 0.2 , $p=0.003$; I2 $=59 \%, p=0.01$ ) (Fig. 3a).

Ten studies was selected to explore the association between vitamin D and FEV1\% $(r=0.27,95 \% \mathrm{CI}=0.22$ to $0.33, p<0.001 ; \mathrm{I} 2=93 \%, P<0.001)$. Three studies $[32,42,48]$ were regarded as homogeneous after a sensitivity analysis and were eliminated from the pooled result $(\mathrm{r}=0.19,95 \% \mathrm{CI}=0.13$ to $0.26, \mathrm{p}<0.001$; I $2=42 \%, P=0.11$ ) (Fig. $3 \mathrm{~b}$ ).

Eight studies explored vitamin D and FVC with the pooled $\mathrm{r}=0.33(95 \% \mathrm{CI}=0.04-0.61, p=0.03)$ and heterogeneity $\mathrm{I} 2=93 \%(p<0.001)$. Three outliers $[6,30,42]$ were removed, resulting in a pooled $\mathrm{r}=0.17(95 \% \mathrm{CI}=$ 0.00 to $0.34, p=0.05)$, I $2=60 \%(p=0.04)$ (Fig. $3 \mathrm{c})$. The pooled correlation between vitamin $\mathrm{D}$ and $\mathrm{FVC} \%$ was $\mathrm{r}=0.08(95 \% \mathrm{CI}=-0.08$ to $0.23, p=0.34)$ with heterogeneity $\mathrm{I} 2=0 \%(p=0.48)$, which did not reach statistical significance (Fig. 3d).

The pooled result of FEV1/FVC with vitamin D was $\mathrm{r}=0.38,(95 \% \mathrm{CI}=0.31$ to $0.45, p<0.001 ; \mathrm{I} 2=90 \%$, $\mathrm{p}<0.001)$. After the sensitivity analysis removed five 


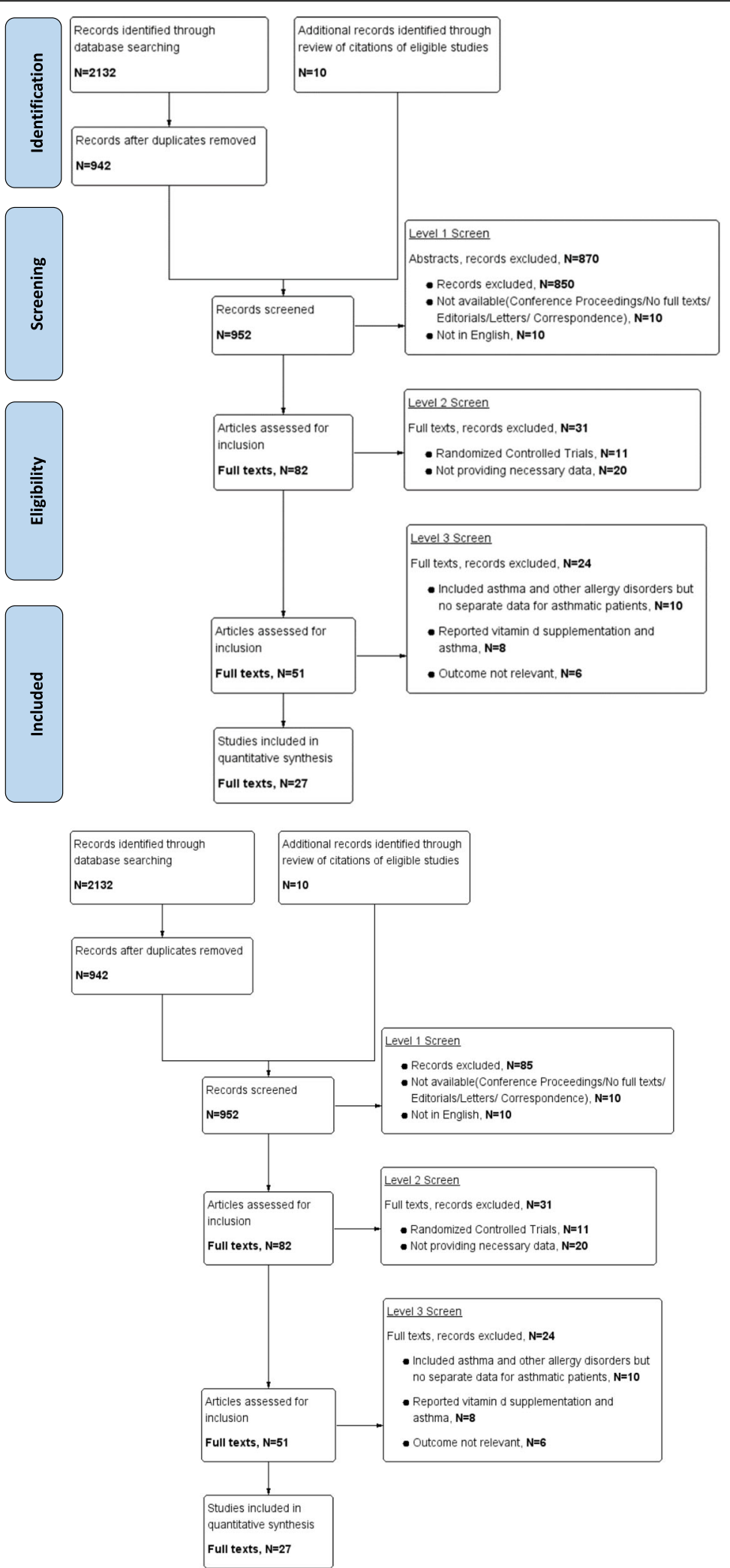

Fig. 1 Flow diagram of study selection process 


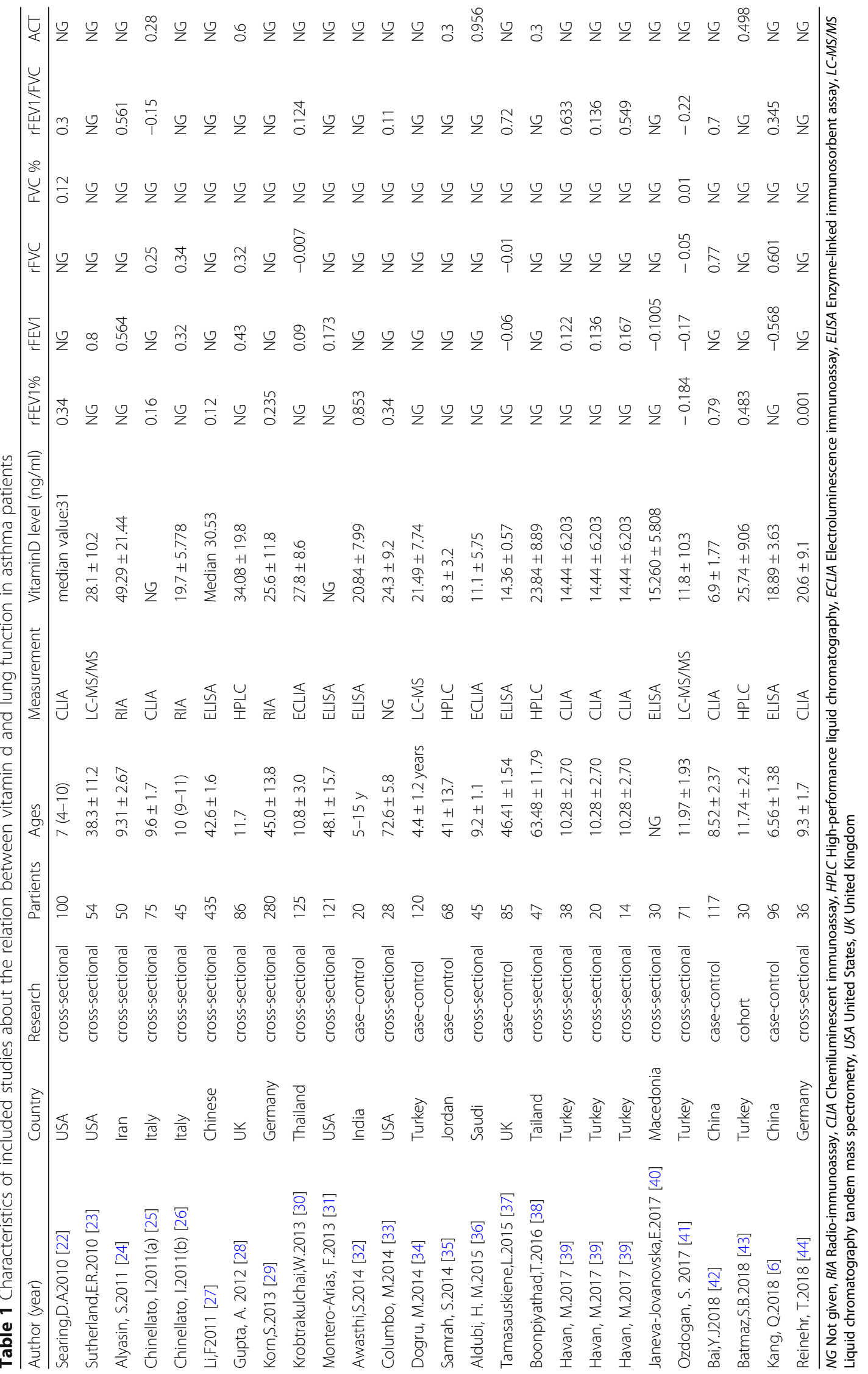


Table 2 Characteristics of the included studies about vitamin d levels in asthma patients

\begin{tabular}{|c|c|c|c|c|c|}
\hline Author (year) & Country & Research type & Measurement & Age & Extracted data \\
\hline Brehm,J.M.2010 [45] & USA & cross-sectional & RIA & $8.9(7.2-10.6)$ & FEV1,FEV1/FVC \\
\hline Alyasin,S.2011 [24] & Iran & cross-sectional & RIA & $9.31 \pm 2.67$ & FEV1/FVC \\
\hline Li,F.2011 [27] & Chinese & cross-sectional & ELISA & $42.6 \pm 1.6$ & FEV1,FEV1/FVC,FEV1\% \\
\hline Brehm,John M.2012 [46] & USA & cross-sectional & HPLC & $10.1 \pm 2.6$ & FEV1,FEV1/FVC \\
\hline Korn,S.2013 [29] & Germany & cross-sectional & RIA & $45.0 \pm 13.8$ & FEV1,FEV1\% \\
\hline Ozdogan, S.2017 [41] & Turkey & cross-sectional & LC-MS/MS & $11.97 \pm 1.93$ & FEV1,FEV1/FVC,FEV1\% \\
\hline Montero-Arias,F.2013 [31] & Costa Rica & cross-sectional & EIA & $48.1 \pm 15.7$ & FEV1/FVC,FEV1\% \\
\hline \multirow[t]{3}{*}{ Wu,A.C.2012 [47] } & Boston & cohort & RIA & $8.94 \pm 2.12$ & FEV1 \\
\hline & & & & & FEV1 \\
\hline & & & & & FEV1 \\
\hline
\end{tabular}

outliers [25,30,37,42,48], we obtained the result of $\mathrm{r}=0.4,(95 \% \mathrm{CI}=0.3$ to $0.51, \mathrm{p}<0.001 ; \mathrm{I} 2=48 \%, p=$ 0.07) (Fig. 3e).

The pooled $\mathrm{r}$ for 6 studies with ACT scores was 0.62 (95\% CI $=0.51$ to $0.73, \mathrm{p}<0.001)$, with $\mathrm{I} 2=94 \%(\mathrm{p}<0.001)$.
Two studies providing discrete values [28, 36] were further excluded with a final result of $\mathrm{r}=0.33,(95 \% \mathrm{CI}=0.2$ to 0.47, $\mathrm{p}<0.001 ; \mathrm{I} 2=0 \%, p=0.7$ ) (Fig. 3f).

Lastly, we performed a subgroup analysis based on two age groups (children and adults). The negative

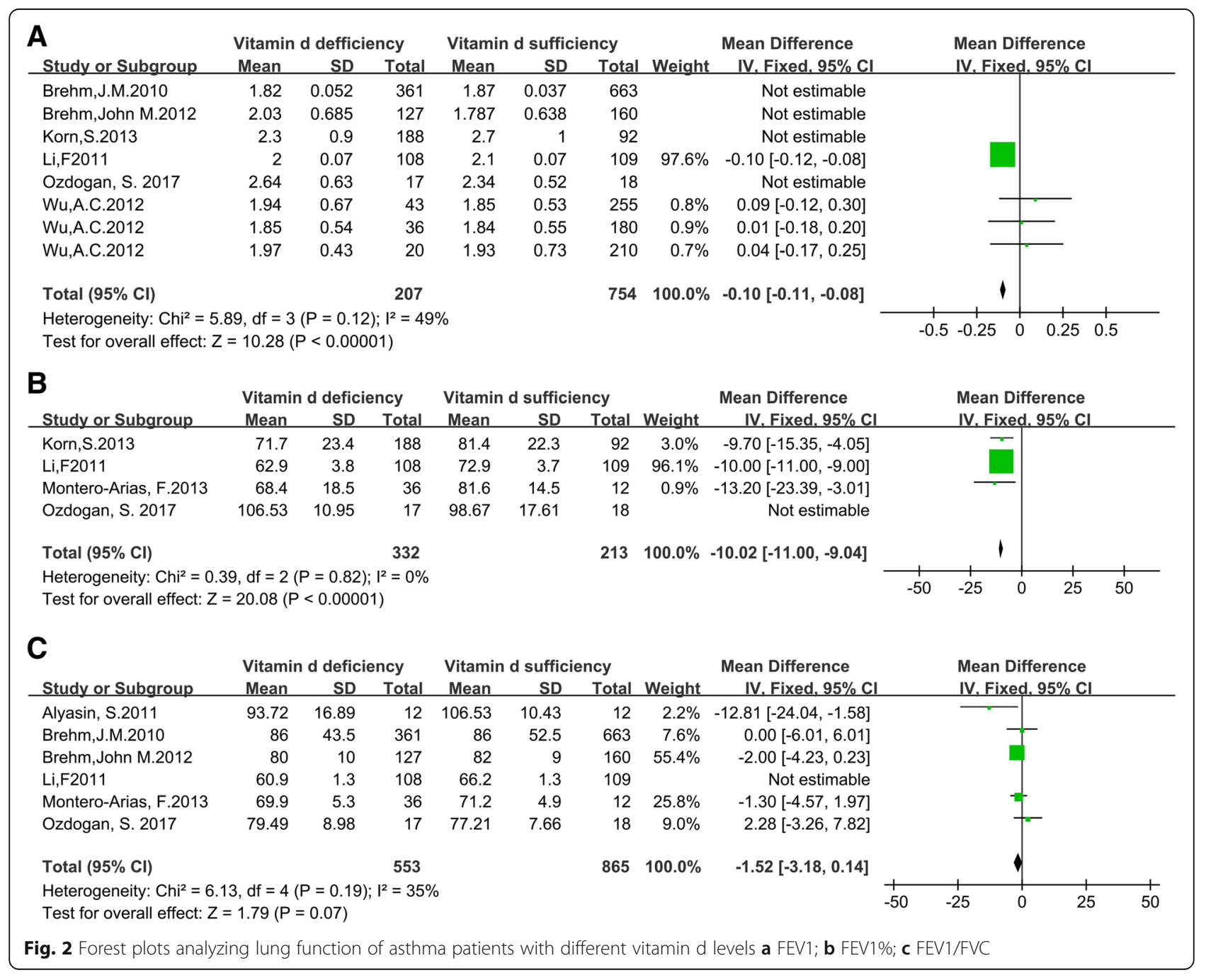




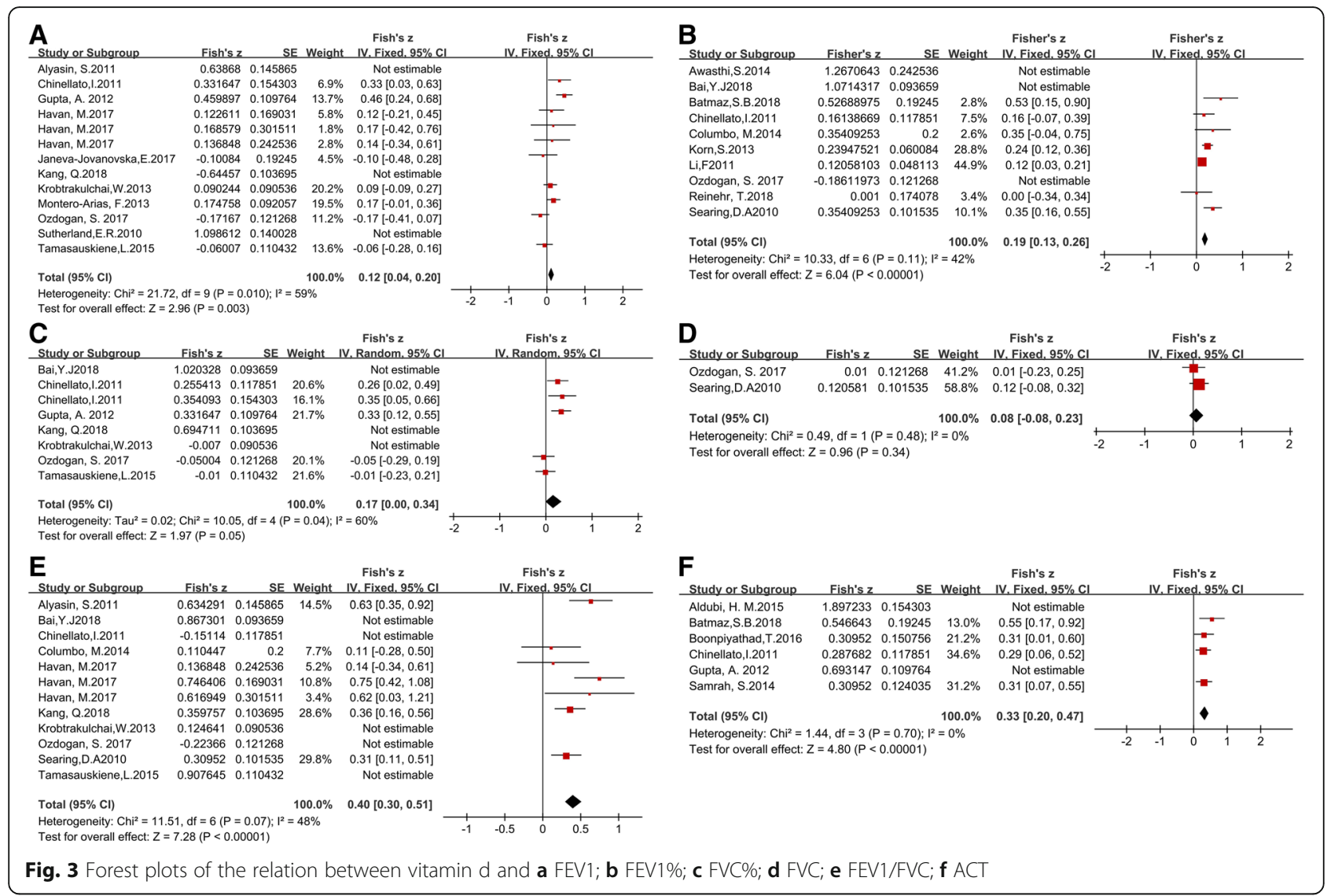

correlation between vitamin D values and lung function in asthma patients remained significant in both age groups (Fig. 4a-d).

\section{Publication bias}

Symmetrical funnel plots suggested no significant publication bias (Additional file 2: Figure S2-Figure S4).

\section{Discussion}

This systematic review and meta-analysis investigated specifically the relation between vitamin D and lung function in both adults and children with asthma. We identified 27 studies with independent data and found that serum vitamin D was positively correlated with lung function in asthma patients, as determined by FEV1, FEV1\%, FEV1/FVC, FVC\%, FVC and ACT scores. Subgroups analysis revealed that this positive correlation exists irrespective of age. Furthermore, participants with insufficient or deficient vitamin D levels have slightly poorer lung function than those with sufficient levels. Inspection of the included studies revealed some heterogeneity in the duration of therapy, categorization threshold and population. Our research outcome confirmed the results reported by Zhang LL [9], in which vitamin D deficiency mirrored a remarkable decrease in lung function in asthmatic children. However, our evidence is much more robust, as we included more recent published studies.

vitamin D receptors (VDRs) are widely distributed in respiratory epithelial cells and immune cells (B cell, T cell, macrophages and monocytes) [27, 49], and the active form of vitamin D $(1,25(\mathrm{OH}) 2 \mathrm{D} 3)$ exerts its physiological effects by binding to VDRs. Binding of vitamin $\mathrm{D}$ the VDR strengthens the coactivation of VDR with the retinoid $\mathrm{X}$ receptor (RXR). Vitamin D combined with VDR-RXR heterodimers interact with vitamin $\mathrm{D}$ response elements (VDREs) to promote vitamin D-regulated gene transcription. The gene encoding 25-dihydroxy vitamin D3 24hydroxylase, CYP24A, is the well-known 1,25(OH)2D3responsive gene and has various VDREs in its promoter. CYP24A belongs to the cytochrome P450 (CYP) family. The P450 (CYP) family encodes multiple enzymes that are used in the oxidative metabolism of many endogenous and exogenous compounds [50,51].

Considering the presence of VDRs on immune cells and various tissues in the airways, the role of vitamin $\mathrm{D}$ as a potentially modifiable factor in asthma has generated much interest regarding its purported immunomodulatory function. Serum $25(\mathrm{OH}) \mathrm{D}$ is used as a marker of vitamin D standards clinically [52]. The activating enzyme 1a- 


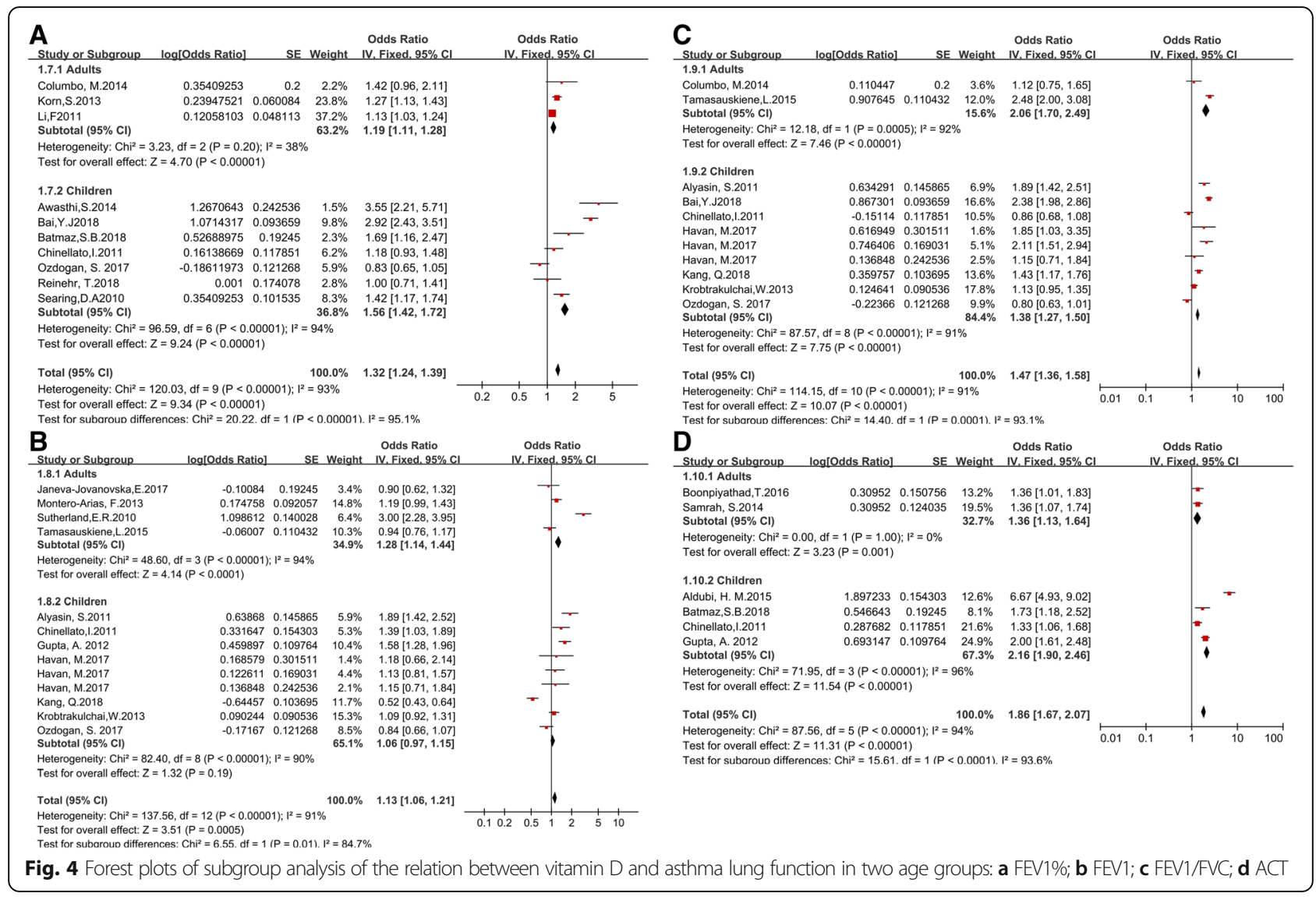

hydroxylase is expressed by respiratory epithelial cells, and converts inactive $25(\mathrm{OH}) \mathrm{D}$ to the active $1,25(\mathrm{OH}) 2 \mathrm{D}$ form [53-55]. Through binding to VDRs, 1,25(OH)2D directly or indirectly interacts with various immune cells. VDRs regulate the transcription of diverse genes related to immunomodulation and inflammation [56]. In addition, vitamin D inhibits IL-4-mediated expression of IL-13 and the proinflammatory cytokines IL-17, and accelerates Tregulatory cell (Treg) secretion of anti-inflammatory cytokines, such as IL-10 [57, 58]. Additionally, 25(OH)2D may shift the balance of the T-regulatory lymphocyte reaction from the $\mathrm{TH} 1$ phenotype to the relatively less inflammatory TH2 phenotype $[59,60]$.

Our findings of the correlation between serum 25(OH)D concentrations and asthma lung function are supported by the current biological knowledge. In terms of the Impact on lung structural development: vitamin D deficiency could exacerbate lung structure and generate deficits in lung function, thus creating permanent susceptibility to poorer respiratory outcomes. In terms of airway smooth muscle (ASM) remodelling: ASM cells possess the enzymatic mechanisms to transform 25 -hydroxy vitamin D to 1 , 25-dihydroxy vitamin D, and 1, 25-dihydroxy vitamin D in turn inhibits ASM proliferation and suppresses expression of inflammatory chemokines [31, 61, 62]. The precise signalling mechanisms remain unclear, but may involve the phosphorylation of checkpoint kinase- 1 and the diminished hyperphosphorylation of retinoblastoma protein induced by PDGF [63-65]. This process further leads to a decline in airflow and a decrease in small airway obstruction, which has direct relevance for lung function and airway remodelling in asthma patients [66]. Immunomodulation with vitamin $\mathrm{D}$ added to human monocytes may restrain the expression of Toll-like receptors 2 and 4, resulting in reduced tumour necrosis factor alpha (TNF-a) production. In terms of anti-inflammatory influence: vitamin $\mathrm{D}$ receptor (VDR) could suppress NF-kB activation and signaling, and vitamin $\mathrm{D}$ could inhibit the synthesis of pro-inflammatory cell factors. In terms of changing the outcome of anti-asthmatic therapy: vitamin D could enhance corticosteroid responsiveness through increasing mitogen-activated protein kinase 1 (MKP-1), which is a protein involved in directing cellular responses to a diverse array of stimuli. The VDR may cause downregulation of corticosteroid pathways. In terms of respiratory tract infections: vitamin $\mathrm{D}$ deficiency can induce infections by influencing the production of antimicrobial peptides. 1, $25(\mathrm{OH}) 2 \mathrm{D}$ was found to be related to an antimicrobial peptide called cathelicidin $[67,68]$. This peptide colocalises within phagosomes and is known to be active against a 
wide variety of mycobacteria, viruses, bacteria and fungi. Through these mechanisms, vitamin D deficiency can lead to a higher susceptibility to infection, poorer lung function and more severe asthma exacerbations.

When the correlation coefficient group was further subgrouped into two age groups, children (ages $<18$ years) and adults (ages $>18$ years), we found the reported associations were still significant in both subgroups. This finding differs from previous studies that reported a negative correlation only in the paediatric group [69-71]. A possible explanation may be that the serum vitamin $\mathrm{D}$ levels were the same in the adults and the children $(21.5 \pm 11.40 \mathrm{ng} / \mathrm{ml}$ and $21.11 \pm 14.50 \mathrm{ng} / \mathrm{ml}, p>0.05)$. Further studies are needed to determine whether serum IgE levels and serum vitamin D are inversely related in the two age groups, which could help to confirm that vitamin $\mathrm{D}$ supplementation may be beneficial in downregulating allergic responses in adults and children.

There was a positive trend in the relation between vitamin $\mathrm{D}$ and two indexes (FEV1/FVC and $\mathrm{FVC} \%$ ), but it did not reach significance. This finding may be due to the relatively small number of included studies and the high between-study heterogeneity.

Our study has several strengths. First, compared to previous related systematic reviews, we identified more observational studies (both case-control and cohort) in the analysis. Second, as a consequence of our more comprehensive approach to includ studies, along with data abstraction and meticulous risk of bias evaluation methodology with the risk of bias tool recommended by the Cochrane Collaboration [31, 62], we were able to identify the presence of heterogeneity between studies, which led to a more conservative conclusion. Third, the proportion of the selected participants with missing outcome data was small, and serum 25(OH)D levels were measured with validated assays in high quality laboratories. Fourth, as this meta-analysis was based on published literature, publication bias that results from a tendency to report only positive results is also a consideration. However, the symmetric funnel plot indicated that such bias was minimal.

Some limitations also existed in our studies. The power for some subgroup analyses was limited, and relatively large heterogeneity was noted; this problem is unavoidable, considering the small number of studies reporting data from adults in this field. Moreover, most of the studies evaluated only one measurement of circulating 25(OH)D levels, and the time for the blood sample collection was not always consistent. Furthermore, different therapeutic drugs can modulate serum vitamin D levels. Nevertheless, the results remained concordant in terms of the extracted correlation coefficient, and most of our final results exhibited no significant heterogeneity. Finally, we are unable to use these results to propose specific treatment strategies because of limited information.

\section{Conclusion}

The pooled estimates from the observational studies show that high blood vitamin D levels can benefit lung function and slow asthma exacerbation. Due to the limited data, we are unable to determine an optimal cutoff dose of vitamin D for asthma lung function and control. More comprehensive randomised controlled clinical trials with sufficient power and longer follow-up duration are needed to confirm the results.

\section{Additional files}

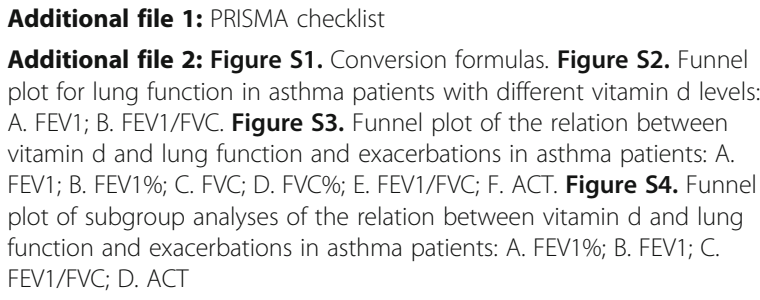

Additional file 2: Figure S1. Conversion formulas. Figure S2. Funnel plot for lung function in asthma patients with different vitamin d levels: A. FEV1; B. FEV1/FVC. Figure S3. Funnel plot of the relation between vitamin $\mathrm{d}$ and lung function and exacerbations in asthma patients: $\mathrm{A}$. FEV1; B. FEV1\%; C. FVC; D. FVC\%; E. FEV1/FVC; F. ACT. Figure S4. Funnel plot of subgroup analyses of the relation between vitamin $d$ and lung function and exacerbations in asthma patients: A. FEV1\%; B. FEV1; C. FEV1/FVC; D. ACT

\section{Abbreviations}

ACT: Asthma control test; ASM: Airway smooth muscle; FEV1: Forced expiratory volume in one second; FVC: Forced vital capacity; MOOSE: Meta-analysis of Observational Studies in Epidemiology; NOS: Newcastle-Ottawa Scale; PRISMA: Preferred Reporting Items for Systematic Reviews and Meta-Analyses; r: Correlation coefficient; RXR: Retinoid X receptor; SE: Standard errors; TH: T helper; TNF-a: Tumour necrosis factor alpha; USA: United States of America; VDREs: Vitamin D response elements; VDRs: Vitamin D receptors

\section{Acknowledgements}

The authors are grateful to all the participants in this research.

\section{Funding}

This work was supported by the Zhejiang Province Public Welfare Technology Application Research Project (CN), China (2019 LGF19H010009). The funders had no role in the study design, data collection and analysis, decision to publish, interpretation of data and preparation of the manuscript.

Availability of data and materials

We declare that the data supporting the conclusions of this article are described in the article.

\section{Authors' contributions}

Conceived and designed the experiments: J. L, Y.Q.D, J. Y, W.F.W. Performed the experiments: J. L, Y.Q.D, J. Y, W.F.W. Analyzed the data: J. L, J.Y, J.S. Contributed reagents/materials/analysis tools: J. L, Y.Q.D, J. Y, G.J.S, K. L, H.F.L, X.F. Wrote the manuscript: J. L Y.Q.D. All authors read and approved the final manuscript.

Ethics approval and consent to participate Not applicable.

Consent for publication

Not applicable.

Competing interests

The authors declare that they have no competing interests to disclose.

\section{Publisher's Note}

Springer Nature remains neutral with regard to jurisdictional claims in published maps and institutional affiliations. 


\section{Author details}

'Department of Intensive Care Unit, the First Affiliated Hospital, College of Medicine, Zhejiang University, Hangzhou, Zhejiang Province, China. ${ }^{2}$ Department of Respiratory Disease, Yinzhou No. 2 Hospital, Ningbo, Zhejiang Province, China. ${ }^{3}$ Department of Emergency, People's Hospital of Jinyun County, LiuShui, Zhejiang Province, China. ${ }^{4}$ Department of Medical Oncology, The First Affiliated Hospital, College of Medicine, Zhejiang University, Hangzhou, Zhejiang Province, China.

\section{Received: 7 January 2019 Accepted: 13 May 2019}

\section{Published online: 08 October 2019}

\section{References}

1. To T, Stanojevic S, Moores G, Gershon AS, Bateman ED, Cruz AA, Boulet LP. Global asthma prevalence in adults: findings from the cross-sectional world health survey. BMC Public Health. 2012;12:204.

2. Yin $\mathrm{GQ}$, Jiang $\mathrm{WH}, \mathrm{Wu} P Q$, He CH, Chen RS, Deng L. Clinical evaluation of sublingual administration of dust mite drops in the treatment of allergic asthma and allergic rhinitis of children. Eur Rev Med Pharmacol Sci. 2016;20:4348-53.

3. Wu AC, Tantisira K, Li L, Fuhlbrigge AL, Weiss ST, Litonjua A. Effect of vitamin $\mathrm{D}$ and inhaled corticosteroid treatment on lung function in children. Am J Respir Crit Care Med. 2012;186:508-13.

4. Brehm JM, Schuemann B, Fuhlbrigge AL, Hollis BW, Strunk RC, Zeiger RS, Weiss ST, Litonjua AA. Serum vitamin D levels and severe asthma exacerbations in the childhood asthma management program study. J Allergy Clin Immunol. 2010;126:52-58.e55.

5. Ginde AA, Mansbach JM, Camargo CA Jr. Association between serum 25-hydroxyvitamin $D$ level and upper respiratory tract infection in the third National Health and nutrition examination survey. Arch Intern Med. 2009;169:384-90.

6. Kang $Q$, Zhang $X$, Liu S, Huang F. Correlation between the vitamin D levels and asthma attacks in children: evaluation of the effects of combination therapy of atomization inhalation of budesonide, albuterol and vitamin D supplementation on asthmatic patients. Exp Ther Med. 2018;15:727-32.

7. Fares MM, Alkhaled LH, Mroueh SM, Akl EA. Vitamin D supplementation in children with asthma: a systematic review and meta-analysis. BMC Res Notes. 2015;8:23.

8. Luo J, Liu D, Liu CT. Can vitamin D supplementation in addition to asthma controllers improve clinical outcomes in patients with asthma?: a metaanalysis. Medicine (Baltimore). 2015;94:e2185.

9. Zhang LL, Gong J, Liu CT. Vitamin D with asthma and COPD: not a false hope? A systematic review and meta-analysis. Genet Mol Res. 2014;13:7607-16.

10. Wang M, Liu M, Wang C, Xiao Y, An T, Zou M, Cheng G. Association between vitamin $D$ status and asthma control: a meta-analysis of randomized trials. Respir Med. 2019;150:85-94.

11. Jat KR, Khairwa A. Vitamin D and asthma in children: a systematic review and meta-analysis of observational studies. Lung India. 2017;34:355-63.

12. Pojsupap S, lliriani K, Sampaio TZ, O'Hearn K, Kovesi T, Menon K, McNally JD. Efficacy of high-dose vitamin $D$ in pediatric asthma: a systematic review and meta-analysis. J Asthma. 2015;52:382-90.

13. Stroup DF, Berlin JA, Morton SC, Olkin I, Williamson GD, Rennie D, Moher D, Becker BJ, Sipe TA, Thacker SB. Meta-analysis of observational studies in epidemiology: a proposal for reporting. Meta-analysis of observational studies in epidemiology (MOOSE) group. Jama. 2000;283:2008-12.

14. Moher D, Liberati A, Tetzlaff J, Altman DG. Preferred reporting items for systematic reviews and meta-analyses: the PRISMA statement. I Clin Epidemiol. 2009;62:1006-12.

15. Higgins JP, Green S: Cochrane Handbook for Systematic Reviews of Interventions. Wiley; 2011.

16. Wells GA, Shea B, O'Connell D, Peterson J, Welch V, Losos M, Tugwell P. The Newcastle-Ottawa Scale (NOS) for assessing the quality of nonrandomised studies in meta-analyses. Ottawa: Ottawa Hospital Research Institute; 2009.

17. Chalkidou A, Landau DB, Odell EW, Cornelius VR, O'Doherty MJ, Marsden PK. Correlation between Ki-67 immunohistochemistry and 18F-fluorothymidine uptake in patients with cancer: a systematic review and meta-analysis. Eur J Cancer. 2012:48:3499-513.

18. Tsiligianni I, Kocks J, Tzanakis N, Siafakas N, van der Molen T. Factors that influence disease-specific quality of life or health status in patients with COPD: a review and meta-analysis of Pearson correlations. Prim Care Respir J. 2011;20:257-68.
19. Higgins JP, Thompson SG, Deeks JJ, Altman DG. Measuring inconsistency in meta-analyses. Bmj. 2003;327:557-60.

20. DerSimonian R, Laird N. Meta-analysis in clinical trials. Control Clin Trials. 1986;7:177-88.

21. Mantel N, Haenszel W. Statistical aspects of the analysis of data from retrospective studies of disease. J Natl Cancer Inst. 1959;22:719-48.

22. Searing DA, Zhang Y, Murphy JR, Hauk PJ, Goleva E, Leung DY. Decreased serum vitamin $D$ levels in children with asthma are associated with increased corticosteroid use. J Allergy Clin Immunol. 2010;125:995-1000.

23. Sutherland ER, Goleva E, Jackson LP, Stevens AD, Leung DY. Vitamin D levels, lung function, and steroid response in adult asthma. Am J Respir Crit Care Med. 2010;181:699-704.

24. Alyasin S, Momen T, Kashef S, Alipour A, Amin R. The relationship between serum 25 hydroxy vitamin d levels and asthma in children. Allergy Asthma Immunol Res. 2011;3:251-5.

25. Chinellato I, Piazza M, Sandri M, Peroni D, Piacentini G, Boner AL. Vitamin D serum levels and markers of asthma control in Italian children. J Pediatr. 2011;158:437-41.

26. Chinellato I, Piazza M, Sandri M, Peroni DG, Cardinale F, Piacentini GL, Boner AL. Serum vitamin D levels and exercise-induced bronchoconstriction in children with asthma. Eur Respir J. 2011;37:1366-70.

27. Li F, Peng M, Jiang L, Sun Q, Zhang K, Lian F, Litonjua AA, Gao J, Gao X. Vitamin $D$ deficiency is associated with decreased lung function in Chinese adults with asthma. Respiration. 2011;81:469-75.

28. Gupta A, Sjoukes A, Richards D, Banya W, Hawrylowicz C, Bush A, Saglani S. Relationship between serum vitamin $D$, disease severity, and airway remodeling in children with asthma. Am J Respir Crit Care Med. 2011;184:1342-9.

29. Korn S, Hubner M, Jung M, Blettner M, Buhl R. Severe and uncontrolled adult asthma is associated with vitamin D insufficiency and deficiency. Respir Res. 2013;14:25.

30. Krobtrakulchai W, Praikanahok J, Visitsunthorn N, Vichyanond P, Manonukul K, Pratumvinit B, Jirapongsananuruk $\mathrm{O}$. The effect of vitamin d status on pediatric asthma at a university hospital, Thailand. Allergy Asthma Immunol Res. 2013;5:289-94.

31. Montero-Arias F, Sedo-Mejia G, Ramos-Esquivel A. Vitamin d insufficiency and asthma severity in adults from Costa Rica. Allergy Asthma Immunol Res. 2013;5:283-8.

32. Awasthi S, Vikram K. Serum 25 hydroxy vitamin D insufficiency associated with bronchial asthma in Lucknow, India. Indian J Pediatr. 2014;81:644-9.

33. Columbo M, Panettieri RA Jr, Rohr AS. Asthma in the elderly: a study of the role of vitamin D. Allergy Asthma Clin Immunol. 2014;10:48.

34. Dogru M, Kirmizibekmez H, Yesiltepe Mutlu RG, Aktas A, Ozturkmen S. Clinical effects of vitamin D in children with asthma. Int Arch Allergy Immunol. 2014;164:319-25.

35. Samrah S, Khatib I, Omari M, Khassawneh B, Momany S, Daoud A, Malkawi $M$, Khader $Y$. Vitamin $D$ deficiency and level of asthma control in women from north of Jordan: a case-control study. J Asthma. 2014;51:832-8.

36. Aldubi HM, Alissa EM, Kamfar HZ, Gaber O, Marzouki ZM. Bronchial asthma and hypovitaminosis D in Saudi children. Asia Pac Allergy. 2015;5:103-13.

37. Tamasauskiene L, Gasiuniene E, Lavinskiene S, Sakalauskas R, Sitkauskiene B. Evaluation of vitamin D levels in allergic and non-allergic asthma. Medicina (Kaunas). 2015;51:321-7.

38. Boonpiyathad T, Chantveerawong T, Pradubpongsa P, Sangasapaviliya A. Serum vitamin D levels and vitamin D supplement in adult patients with asthma exacerbation. J Allergy (Cairo). 2016;2016:4070635.

39. Havan M, Razi CH, Bulus AD, Koksal AO, Andiran N. Effects of 25 hydroxy vitamin $D$ levels on the severity and asthma control in school age asthma patients. Arch Argent Pediatr. 2017;115:336-42.

40. Janeva-Jovanovska E, Dokic D, Jovkovska-Kaeva B, Breskovska G, Goseva Z, Minov J, Trajkov D, Dimitrova-Genadieva M, Zafirovska-Ivanovska B. Relationship between vitamin $D$, inflammation and lung function in patients with severe uncontrolled asthma. Open Access Maced J Med Sci. 2017;5:899-903.

41. Ozdogan S, Sari G, Aktan IH, Aydin B, Irmak C, Cavdar S. Vitamin D status, lung function and Atopy in children with asthma. J Coll Physicians Surg Pak. 2017;27:292-5.

42. Bai YJ, Dai RJ. Serum levels of vitamin a and 25-hydroxyvitamin D3 (25OHD3) as reflectors of pulmonary function and quality of life (QOL) in children with stable asthma: a case-control study. Medicine (Baltimore). 2018;97:e9830.

43. Batmaz SB, Arikoglu T, Tamer L, Eskandari G, Kuyucu S. Seasonal variation of asthma control, lung function tests and allergic inflammation in 
relation to vitamin $D$ levels: a prospective annual study. Postepy Dermatol Alergol. 2018:35:99-105.

44. Reinehr T, Langrock C, Hamelmann E, Lucke T, Koerner-Rettberg C, Holtmann M, Legenbauer T, Gest S, Frank M, Schmidt B, et al. 25Hydroxvitamin D concentrations are not lower in children with bronchial asthma, atopic dermatitis, obesity, or attention-deficient/hyperactivity disorder than in healthy children. Nutr Res. 2018;52:39-47.

45. Brehm JM, Schuemann B, Fuhlbrigge AL, Hollis BW, Strunk RC, Zeiger RS, Weiss ST, Litonjua AA. Childhood asthma management program research $G$. serum vitamin D levels and severe asthma exacerbations in the childhood asthma management program study. J Allergy Clin Immunol. 2010;126:52-8 e55.

46. Brehm JM, Acosta-Pérez E, Klei L, Roeder K, Barmada M, Boutaoui N, Forno E, Kelly $R$, Paul K, Sylvia J, et al. Vitamin D insufficiency and severe asthma exacerbations in Puerto Rican children. Am J Respir Crit Care Med. 2012;186:140-6.

47. Wu AC, Tantisira K, Li L, Fuhlbrigge AL, Weiss ST, Litonjua A. Childhood asthma management program research $G$. effect of vitamin $D$ and inhaled corticosteroid treatment on lung function in children. Am J Respir Crit Care Med. 2012;186:508-13.

48. Ozdogan S. Vitamin-D-status-lung-function-and-Atopy-in-children-withasthma 2017.

49. Lange NE, Litonjua A, Hawrylowicz CM, Weiss S. Vitamin D, the immune system and asthma. Expert Rev Clin Immunol. 2009;5:693-702

50. Plum LA, DeLuca HF. Vitamin D, disease and therapeutic opportunities. Nat Rev Drug Discov. 2010;9:941-55.

51. Goleva E, Searing DA, Jackson LP, Richers BN, Leung DY. Steroid requirements and immune associations with vitamin $\mathrm{D}$ are stronger in children than adults with asthma. J Allergy Clin Immunol. 2012;129:1243-51.

52. Holick MF. Vitamin D deficiency. N Engl J Med. 2007;357:266-81.

53. Hansdottir S, Monick MM, Hinde SL, Lovan N, Look DC, Hunninghake GW. Respiratory epithelial cells convert inactive vitamin $D$ to its active form: potential effects on host defense. J Immunol. 2008;181:7090-9.

54. Hansdottir S, Monick MM. Vitamin D effects on lung immunity and respiratory diseases. Vitam Horm. 2011;86:217-37.

55. Hansdottir S, Monick MM, Lovan N, Powers L, Gerke A, Hunninghake GW. Vitamin D decreases respiratory syncytial virus induction of NF-kappaBlinked chemokines and cytokines in airway epithelium while maintaining the antiviral state. J Immunol. 2010;184:965-74.

56. Espana PP, Capelastegui A, Gorordo I, Esteban C, Oribe M, Ortega M, Bilbao A, Quintana JM. Development and validation of a clinical prediction rule for severe community-acquired pneumonia. Am J Respir Crit Care Med. 2006;174:1249-56.

57. Brown SD, Calvert HH, Fitzpatrick AM. Vitamin D and asthma. Dermatoendocrinol. 2012:4:137-45.

58. Paul G, Brehm JM, Alcorn JF, Holguin F, Aujla SJ, Celedon JC. Vitamin D and asthma. Am J Respir Crit Care Med. 2012;185:124-32.

59. Litonjua AA, Weiss ST. Is vitamin D deficiency to blame for the asthma epidemic? J Allergy Clin Immunol. 2007;120:1031-5.

60. Camargo CA Jr, Ingham T, Wickens K, Thadhani R, Silvers KM, Epton MJ, Town Gl, Pattemore PK, Espinola JA, Crane J. Cord-blood 25-hydroxyvitamin $D$ levels and risk of respiratory infection, wheezing, and asthma. Pediatrics. 2011;127:e180-7.

61. Sandhu MS, Casale TB. The role of vitamin D in asthma. Ann Allergy Asthma Immunol. 2010;105:191-9 quiz 200-192, 217.

62. Matheu V, Back O, Mondoc E, Issazadeh-Navikas S. Dual effects of vitamin Dinduced alteration of $\mathrm{TH} 1 / \mathrm{TH} 2$ cytokine expression: enhancing lgE production and decreasing airway eosinophilia in murine allergic airway disease. J Allergy Clin Immunol. 2003;112:585-92.

63. Kumar J, Muntner P, Kaskel FJ, Hailpern SM, Melamed ML. Prevalence and associations of 25-hydroxyvitamin D deficiency in US children: NHANES 2001-2004. Pediatrics. 2009;124:e362-70

64. Roth M, Johnson PR, Borger P, Bihl MP, Rudiger JJ, King GG, Ge Q, Hostettler $\mathrm{K}$, Burgess JK, Black JL, et al. Dysfunctional interaction of C/EBPalpha and the glucocorticoid receptor in asthmatic bronchial smooth-muscle cells. N Engl J Med. 2004;351:560-74.

65. Bernardi RJ, Trump DL, Yu WD, McGuire TF, Hershberger PA, Johnson CS. Combination of 1alpha,25-dihydroxyvitamin D(3) with dexamethasone enhances cell cycle arrest and apoptosis: role of nuclear receptor cross-talk and Erk/Akt signaling. Clin Cancer Res. 2001;7:4164-73.
66. Bener A, Ehlayel MS, Bener HZ, Hamid Q. The impact of vitamin D deficiency on asthma, allergic rhinitis and wheezing in children: An emerging public health problem. J Family Commun Med. 2014;21:154-61.

67. Yim S, Dhawan P, Ragunath C, Christakos S, Diamond G. Induction of cathelicidin in normal and CF bronchial epithelial cells by 1,25-dihydroxyvitamin D(3). J Cyst Fibros. 2007;6:403-10.

68. Gombart AF, Borregaard N, Koeffler HP. Human cathelicidin antimicrobial peptide (CAMP) gene is a direct target of the vitamin $D$ receptor and is strongly up-regulated in myeloid cells by 1,25-dihydroxyvitamin D3. FASEB J. 2005;19:1067-77.

69. Brehm JM, Celedon JC, Soto-Quiros ME, Avila L, Hunninghake GM, Forno E, Laskey D, Sylvia JS, Hollis BW, Weiss ST, et al. Serum vitamin D levels and markers of severity of childhood asthma in Costa Rica. Am J Respir Crit Care Med. 2009;179:765-71.

70. Sharief S, Jariwala S, Kumar J, Muntner P, Melamed ML. Vitamin D levels and food and environmental allergies in the United States: results from the National Health and nutrition examination survey 2005-2006. J Allergy Clin Immunol. 2011;127:1195-202.

71. Majak P, Olszowiec-Chlebna M, Smejda K, Stelmach I. Vitamin D supplementation in children may prevent asthma exacerbation triggered by acute respiratory infection. J Allergy Clin Immunol. 2011;127:1294-6.

\section{Ready to submit your research? Choose BMC and benefit from:}

- fast, convenient online submission

- thorough peer review by experienced researchers in your field

- rapid publication on acceptance

- support for research data, including large and complex data types

- gold Open Access which fosters wider collaboration and increased citations

- maximum visibility for your research: over $100 \mathrm{M}$ website views per year

At BMC, research is always in progress.

Learn more biomedcentral.com/submissions 